\title{
Post Exposure Management of H1N1 flu
}

\section{Patel $\mathbf{U}^{1}$, Gedam DS}

Dr. Umesh Patel, Associate Professor, Department of Pediatrics, LN Medical College, Bhopal, MP, Dr. D. Sharad Gedam, Professor, Department of Pediatrics, LN Medical College, Bhopal, MP, India

Address for Correspondence: Dr. Umesh Patel, Email: drumeshpatel@gmail.com

\begin{abstract}
Although influenza is recognized as an important cause of acute respiratory illness, little is known about the prevalence and burden of influenza in India
\end{abstract}

Key words: Post Exposure Management, H1N1 flu, H1N1 influenza viruses

H1N1 influenza viruses continued to be the predominant circulating influenza viruses. WHO declared pandemic of H1N1on June 11, 2009 [1]. Although influenza is recognized as an important cause of acute respiratory illness, little is known about the prevalence and burden of influenza in India. 2015 Indian swine flu outbreak refers to a outbreak of the 2009 pandemic H1N1 virus in India, which is still ongoing as of March 2015 [2]. The states of Gujarat and Rajasthan are the worst affected [3]. The H1N1 virus outbreak had previously occurred India during the 2009 flu pandemic. Immediately after the emergence of pdm H1N1 in May 2009, the strain largely replaced the circulating seasonal Inf A (H1N1) and Inf A (H3N2) viruses. From 2010 onwards, the pandemic strain pdm H1N1 virus continued to circulate in India, but, along with the previously circulating influenza viruses; InfA (H3N2) and InfB, replacing completely the seasonal Inf A (H1N1) [4]. Below mentioned table shows total death due to H1N1 since 2009[5].

\begin{tabular}{|l|l|l|}
\hline S.No & Year & Deaths \\
\hline 01 & 2009 & 981 \\
\hline 02 & 2010 & 1763 \\
\hline 03 & 2011 & 11 \\
\hline 04 & 2012 & 405 \\
\hline 05 & 2013 & 699 \\
\hline 06 & 2014 & 218 \\
\hline 07 & 2015 & \\
\hline
\end{tabular}

Influenza illness in infants and children may present similarly to other respiratory viruses, and symptoms and presentation may be different than presentation in adults. A wide spectrum of potential influenza-related complications is possible among children. These range from mild-to-moderate complications such as otitis media, sinusitis, myositis, and febrile seizures to more severe manifestations such as myocarditis, pneumonia, encephalitis, invasive bacterial co-infection. Individuals at risk for complications include those younger than 2 or over 65 years; pregnant; or with a weakened immune system such as solid organ transplant recipients [1].
Prophylaxis is recommended for

1. Risk factors for more serious disease: pulmonary (including persistent asthma), cardiovascular, renal, hepatic, hematological (including sickle cell disease), neurologic, neuromuscular, metabolic disorders (including diabetes mellitus), Immunosuppression, including that caused by medications, asplenia, Long-term aspirin therapy

2. Vulnerable settings includes child care centres with baby rooms (under 12 months of age), special schools, aged care facilities, hospitals

Measures to decrease transmission-

1. Household transmission can be reduced by good ventilation and proper hand hygiene.

2. Cough etiquettes

3. Yearly flue vaccination

4. Isolation of flue patient in separated room

5. At least 1 meter distance should be kept between patients, as droplets can travel this distance only

6. Regular disinfection should be done

7. Staff should use well fitting surgical mask that should be change every 4 hours

Postexposure prophylaxis: Post exposure prophylaxis should be considered for contact during the infectious period (e.g., one day before until 7 days after the case's onset of illness). If the contact occurred more than 7 days earlier, then prophylaxis is not necessary. For pre-exposure protection, chemoprophylaxis should be given during the potential exposure period and continued for 10 days after the last known exposure to an ill confirmed case of swine-origin influenza A (H1N1) virus infection. Healthcare personnel are at an increased risk of acquiring infectious diseases like H1N1 due to their occupational exposure and infection control measures need to be undertaken to prevent them. 
Examples of close contact include kissing or embracing, sharing eating or drinking utensils, physical examination, or any other contact between persons likely to result in exposure to respiratory droplets. Close contact typically does not include activities such as walking by an infected person or sitting across from a symptomatic patient in a waiting room or office.

\section{Antiviral medication dosing recommendations for chemoprophylaxis of H1N1 infection for infants and children}

\begin{tabular}{|c|c|c|c|c|}
\hline S.No & Drug & Age Group & \multicolumn{2}{|c|}{ Chemoprophylaxis (10 Days) } \\
\hline \multirow[t]{6}{*}{01} & \multirow[t]{6}{*}{ Oseltamivir } & $\leq 3$ months & \multicolumn{2}{|c|}{$\begin{array}{l}\text { Not recommended unless situation judged critical due to limited data } \\
\text { on use in this age group }\end{array}$} \\
\hline & & $\geq 3$ months & \multicolumn{2}{|c|}{$3 \mathrm{mg} / \mathrm{kg} / \mathrm{dose}$ once per day } \\
\hline & & \multirow{4}{*}{$\geq 12$ months } & $\leq 15 \mathrm{~kg}$ & $30 \mathrm{mg}$ once per day \\
\hline & & & $16-23 \mathrm{~kg}$ & $45 \mathrm{mg}$ once per day \\
\hline & & & $24-40 \mathrm{~kg}$ & $60 \mathrm{mg}$ once per day \\
\hline & & & $\geq 40 \mathrm{~kg}$ & $75 \mathrm{mg}$ once per day \\
\hline \multirow[t]{2}{*}{02} & \multirow[t]{2}{*}{ Zanamivir } & $\leq 5$ years & \multicolumn{2}{|c|}{ Not recommended } \\
\hline & & $\geq 5$ years & \multicolumn{2}{|c|}{$10 \mathrm{mg}$ (two 5-mg inhalations) once daily } \\
\hline
\end{tabular}

It must be remembered that chemoprophylaxis is biggest risk factor for drug resistance. Antiviral therapy has the potential to promote or prevent the emergence of drug resistant viruses. When viral replication is blocked, no drug resistant mutants can emerge. If an antiviral drug is given after the viral population has expanded, or if the amount of drug is not sufficient to block viral replication, genomes that contain mutations will replicate. If the number of viral genomes is small, the infection may be cleared by the immune response. Chemoprophylaxis should be considered only for very highrisk household contacts like pregnant woman and severely immunocompromised [6].

In India recently a systematic laboratory-based surveillance network of influenza viruses was established, that includes sentinel surveillance sites geographically distributed in northern, central, southern, and eastern India. The surveillance network is started generating data, to better understand the circulating subtypes and seasonality in different geographic regions in India [7].

\section{References}

1. US Centers for Disease Control and Prevention: Interim Guidance on Antiviral Recommendations for Patients with Novel Influenza A (H1N1) Virus Infection and Their Close Contacts. May 6, 2009. Available at: http://www.cdc.gov/h1n1flu/recommendations. htm.
2. 'It's H1N1 pandemic influenza 2009, not swine flu'". The Times of India. 20 February 2015. Retrieved 22 December 2015.

3. "Death toll Gujarat". Business Standard. 15 March 2015. Retrieved 22 December 2015.

4. Broor S, Krishnan A, Roy DS, Dhakad S, Kaushik S, Mir MA, et al. Dynamic patterns of circulating seasonal and pandemic A (H1N1) pdm09 influenza viruses from 20072010 in and around Delhi, India. PLoS One. 2012;7:e29129.

5. Swine flu outbreak: 743 deaths, 12,000 cases set alarm bells ringing". Hindustan Times. 21 February 2015. Retrieved 21 December 2015.

6. Baz M, Abed Y, Papenburg J, Bouhy X, Hamelin ME, Boivin G. Emergence of oseltamivir-resistant pandemic H1N1 virus during prophylaxis. N Engl J Med. 2009 Dec 3;361(23):2296-7.

7. Chadha MS, Broor S, Gunasekaran P, Potdar VA, Krishnan A, Chawla-Sarkar M, Biswas D, Abraham AM, Jalgaonkar SV, Kaur H, Klimov A, Lal RB, Moen A, Kant L, Mishra AC. Multisite virological influenza surveillance in India: 20042008. Influenza Other Respir Viruses. 2012 May;6(3):196203.

\section{How to cite this article?}

Patel U, Gedam DS. Post Exposure Management of H1N1 flu. Int J Med Res Rev 2015;3(11):1279-1280. doi: 10.17511/ijmrr.2015.111.250. 